\title{
Sex Difference in the Size of the Neural Song Control Regions in a Dueting Songbird with Similar Song Repertoire Size of Males and Females
}

\author{
Manfred Gahr, Edith Sonnenschein, and Wolfgang Wickler \\ Max-Planck-Institut für Verhaltensphysiologie, 82319 Seewiesen, Germany
}

Previous studies have suggested a causal relation between sex differences in behavior such as singing and sex differences in the size of brain areas such as the forebrain song control areas of songbirds. In the present study we show that the size of the forebrain vocal control areas nucleus hyperstriatalis ventrale pars caudale (HVC) and nucleus robustus archistriatalis (RA) and its neuron numbers are about twice as large in males as in females of the African dueting bush shrike Laniarius funebris. However, song types are of similar complexity (number of elements per song type, physical properties of elements) in both sexes, and repertoire size does not differ between males and females. Furthermore, in captivity male and female shrikes are able to learn the same song types. This demonstrates for the shrike that sex differences in the size of vocal control areas and in its neuron numbers do not predict the type of sex-typical vocal behavior. This result is supported by a statistical comparison of the sex differences in HVC size, RA size, and song repertoire size of all songbird species studied to date. Sex differences in species in which only the males sing are indeed larger than in species in which the females also sing; in songbird species with singing females, however, the sex differences in HVC and RA volume appear to be independent of the vocal repertoire size of females. The songbird model therefore does not support the notion that sex differences in area size and neuron number explain sex differences in a behavior that occurs in both sexes. Furthermore, in the shrike, neuron soma size is similar in males and females in the song motonucleus hypoglossus pars tracheosyringealis (nXIIts) and in the premotor nucleus RA, but is sexually dimorphic in the higher vocal center HVC. Thus, male and female shrikes produce songs of similar complexity with different neuron phenotypes.

Key words: sexual dimorphism; singing; males; females; songbirds; brain space-behavior correlation
Sex differences in behavior, in particular in the realm of reproduction, are common in all vertebrates. Males display, mount, and deposit sperm, and females select a male, solicit copulations, and donate eggs. Such clear-cut behavioral differences between the sexes have led many investigators to hypothesize that males and females must differ fundamentally in the construction of the CNS. Subsequently, since the pioneering work of Raisman and Field (1971), many reports on structural sexual dimorphisms at various organizational levels of CNS of vertebrates have been published (for review, see Arnold and Gorski, 1984; Kelley and Brenowitz, 1992; Gahr, 1994; Francis, 1995).

The notion that these structural sex dimorphisms are indeed causally linked to sex differences in behavior has been supported in part by comparative neuroanatomical work on the vocal control network of songbirds (Nottebohm and Arnold, 1976; Arnold et al., 1986; Ball et al., 1994). In songbirds, a chain of forebrain areas such as nucleus hyperstriatalis ventrale pars caudale (HVC) and nucleus robustus archistriatalis (RA) is required for the production of learned vocal pattern (Nottebohm et al., 1976; Wild, 1994a; Vu et al., 1994). Activity pattern of the forebrain vocal control nuclei HVC and RA appear to be uniquely associated with song syllable and song element identity, respectively (Yu and Margoliash, 1996). These areas seem to differ between males and females in size and neuron numbers in those songbird species in

Received Aug. 11, 1997; revised Nov. 6, 1997; accepted Nov. 11, 1997.

We thank Dr. Evan Balaban, NSI San Diego, for his help with the statistics.

Correspondence should be addressed to Dr. Manfred Gahr, Max-Planck-Institut für Verhaltensphysiologie, 82319 Seewiesen, Germany.

Copyright (C) 1998 Society for Neuroscience $\quad 0270-6474 / 98 / 181124-08 \$ 05.00 / 0$ which males and females differ in their vocal behavior. Across several dueting species of wrens, the degree of sex difference of the size and number of neurons of forebrain vocal control areas and even of the neuron soma size seems to correlate with the degree of sex difference in their song repertoire (Arnold et al., 1986; Brenowitz and Arnold, 1986); female zebra finches do not sing, and their forebrain song nuclei HVC and RA are 5-14 times smaller compared with the singing males (Nottebohm and Arnold, 1976).

This work on songbirds (Nottebohm and Arnold, 1976; Arnold et al., 1986; Brenowitz and Arnold, 1986) has inspired work on many other sexual dimorphic behaviors of vertebrates and led to the notion that size and neuron number correlate with the degree of differentiation of the behavior controlled by that area in the vertebrate brain (for review, see Kelley and Brenowitz, 1992). Here we report now for the first time that brain space and neuron numbers of the song nuclei HVC and RA and even neuron size of the HVC are sexually dimorphic in a dueting species, the African bush shrike Laniarius funebris, with similar song complexity (similar size of song type repertoire, similar numbers of elements per song type, similar physical properties of elements such as degree of frequency modulation and element length) and sound volume in males and females. The singing behavior of this songbird was studied extensively in the field and in captivity during the last 25 years (Wickler, 1972; Sonnenschein and Reyer, 1983; Wickler and Seibt, 1988; Wickler and Sonnenschein, 1989). Additionally, we did a statistical analysis of the correlation of sex differences in HVC size, RA size, and song repertoire size of the bush shrike and of all other songbird species from which these 

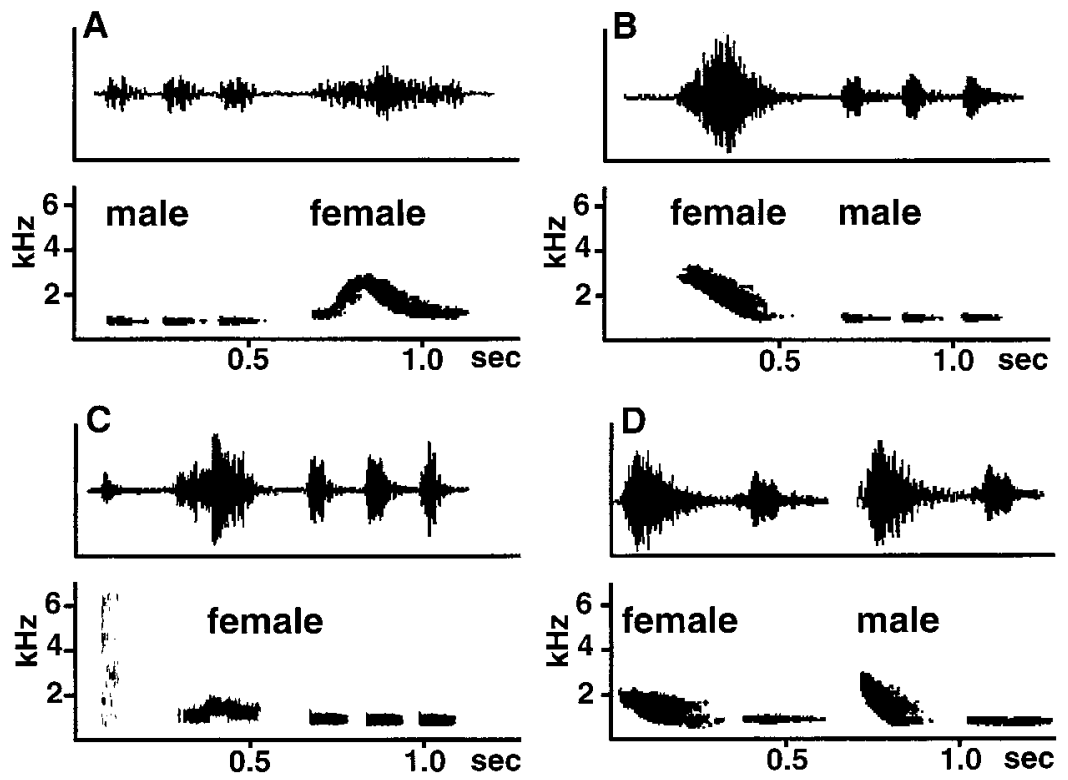

Figure 1. Sonograms and power spectrums of song types of male and female bush shrikes. Males and females are able to produce song type elements of similar physical complexity and even the same song types. $A$ and $B$ show duets that are started by either male $(A)$ or female $(B)$ birds. These song types consist of three elements in the males and one element in the females. In $C$, the song type of a hand-raised female is depicted. This song type consists of five elements; the last three elements are similar to the elements of the males in $A$ and $B . D$ shows a song type that is composed of two elements. This song type is sung only by males in wild populations; in captivity, females learn these song types. data were available. This comparison revealed that the shrike is not an exception among songbirds: there is no correlation between sex differences in the size of vocal areas and singing in species in which females do sing.

\section{MATERIALS AND METHODS}

Animals. Altogether we used 13 birds for the analysis: one wild-caught adult male from a Tanzanian population, two hand-reared birds (one male, one female) that were offsprings from wild pairs in Kenya, and six males and four females raised in captivity in aviaries. All birds had individual repertoires of three to six song types. The birds with the smallest (three) and largest (six) song repertoires were both males. The song behavior and the anatomy of the vocal control areas were studied in the same animals.

Song analysis. We used laparotomy to determine the sex of each bird. To assess the entire repertoire size, it was necessary to observe and record individual birds over a long period of time because the singing rate is seasonal and differs in the sexes. Most of the birds were under observation for several years, e.g., >10 years for the wild-caught Tanzanian bird. Repertoire size remained stable once the bird had reached 1 year of age.

Vocalizations were recorded with a UHER 4200 stereo tape recorder and an AKG D900C directional microphone. Song types were analyzed with the AVISOFT-SONOGRAPH Pro for WINDOWS and compared using sonograms and power spectrums.

Song in both sexes is built from distinct vocal song types. Each song type consists of one or a few elements (Fig. 1). A definite number of song types constitutes the repertoire of the individual bird. Song types are generally uttered in serial repetitions by either one bird alone or by two birds in a duet. Duets result from well timed call-answer sequences of both birds; they last 1-2 sec and contain usually one song type of each partner. In all populations studied in the field, repertoires were clearly sex-specific, but neither the physical characteristics of the song types (elements) nor the number of elements per song type allows a prediction of which will be male or which female (Fig. 1). Furthermore, in captivity, females and males learn to produce song types that are typical of the opposite sex under natural conditions (Fig. 1).

Histology. For the estimation of the volume of the forebrain song areas $\mathrm{HVC}$ and RA, of their neuron numbers, and of the soma size of HVC and RA neurons, we used cytoarchitectural criteria in Nissl-stained brain sections. In addition, for the volumetric measurements of the $\mathrm{HVC}$ we used a biochemical marker (androgen receptor mRNA) because HVC is difficult to delineate in Nissl stainings, which therefore may result in ambiguous volumetric results (Gahr, 1997). The distribution of androgen receptor mRNA in the caudal neostriatum defines the HVC (Nastiuk and Clayton, 1995; Gahr et al., 1996).

Brain sections were prepared as follows. Animals were killed with an overdose of Equithesin and perfused transcardially with $4 \%$ phosphatebuffered paraformaldehyde, and the brains were stored in RNase-free $20 \%$ phosphate-buffered sucrose until they were sectioned. Brains were cut with a freezing microtome alternating in two 20 and two $40 \mu \mathrm{m}$ parasagittal sections under RNase-free conditions. Sections were collected in RNase-free PBS and mounted onto Fisher Superfrost Plus Slides. Each series of 20 and $40 \mu \mathrm{m}$ sections was mounted onto different slides so that we obtained four series of adjacent sections. The two $20 \mu \mathrm{m}$ series were used for in situ hybridizations for androgen receptors (ARs), and one $40 \mu \mathrm{m}$ series was stained with the Nissl dye Thionin.

In situ hybridization. AR-expressing cells were localized in brain sections with cRNA probes of the zebra finch AR by means of in situ hybridization. Details of the cloning of the zebra finch AR are given elsewhere (Gahr and Metzdorf, 1997). This AR fragment has a 96.4\% homology with the AR of the canary (Nastiuk and Clayton, 1994) and a $92 \%$ homology with the AR of the ring dove (Streptopelia risoria) (J. Cao and M. Gahr, unpublished data) and therefore appears to identify AR of the forebrain song nuclei in many songbird species, including the shrike.

For transcription of the antisense or sense probes, the plasmid containing the AR sequence was linearized with NsiI or XhoI and transcribed from the T7 or SP6 promotor, respectively. The synthesis and labeling of the probes with ${ }^{35} \mathrm{~S}-\mathrm{CTP}$ (DuPont NEN, Boston, MA) was performed using the Riboprobe System (Promega, Madison, WI) according to the manufacturer's instructions. The sense probes served as controls in the in situ hybridization studies.

An in situ hybridization procedure previously described by Whitfield et al. (1990) was followed with modifications. Brains were cut into $20 \mu \mathrm{m}$ sagittal sections and mounted onto Fisher Superfrost Plus Slides. Sections were mounted onto different slides so that we obtained three series of adjacent sections that were stained for ARs and with the Nissl dye Thionin. Sections were hybridized under coverslips for $15 \mathrm{hr}$ at $55^{\circ} \mathrm{C}$, using ${ }^{35}$ S-labeled sense or antisense probes $\left(2 \times 10^{7} \mathrm{cpm} / \mathrm{ml}\right)$ in $50 \%$ formamide, $600 \mathrm{~mm} \mathrm{NaCl}, 10 \mathrm{~mm}$ Tris- $\mathrm{HCl}, \mathrm{pH}$ 7.5, 0.02\% Ficoll, $0.02 \%$ BSA, $0.02 \%$ polyvinylpyrrolidone, $1 \mathrm{~mm}$ EDTA, $0.01 \%$ salmon testicular DNA, $0.05 \%$ total yeast RNA, $0.005 \%$ yeast transfer RNA, $10 \%$ dextran sulfate, $0.1 \%$ SDS, $0.1 \%$ sodium thiosulfate, and $100 \mathrm{~mm}$ dithiothreitol. After hybridization, slides were immersed in $2 \times \mathrm{SSC}$ for $30 \mathrm{~min}$ at room temperature to float off the coverslips. The slides were first treated with RNase-A $(20 \mu \mathrm{g} / \mathrm{ml})$ in RNase buffer $(0.5 \mathrm{M} \mathrm{NaCl}, 10 \mathrm{~mm}$ Tris- $\mathrm{HCl}, \mathrm{pH}$ 8.0, $1.0 \mathrm{~mm}$ EDTA) for $30 \mathrm{~min}$ at $37^{\circ} \mathrm{C}$ and washed in the same buffer for $30 \mathrm{~min}$ at $37^{\circ} \mathrm{C}$. The slides were then washed in $2 \times \mathrm{SSC}$ for $1 \mathrm{hr}$ at $50^{\circ} \mathrm{C}$, $0.2 \times \mathrm{SSC}$ for $1 \mathrm{hr}$ at $55^{\circ} \mathrm{C}$, and $0.2 \times \mathrm{SSC}$ for $1 \mathrm{hr}$ at $60^{\circ} \mathrm{C}$, and then dehydrated sequentially before air drying. To detect autoradiographic silver grains, the slides were dipped into Kodak NTB-2 nuclear track emulsion diluted 1:1 with $0.1 \%$ Aerosol 22 (Sigma, St. Louis, MO) at $42^{\circ} \mathrm{C}$ and then exposed at $4^{\circ} \mathrm{C}$ for $7-14 \mathrm{~d}$. The slides were developed in Kodak D19 for $2 \mathrm{~min}$ at $16^{\circ} \mathrm{C}$, rinsed in deionized water for $30 \mathrm{sec}$, fixed 
in Kodak fixer for $5 \mathrm{~min}$, and then washed in deionized water. Sections were counterstained with Thionin and examined using bright- and darkfield illumination.

Morphometric analysis. Because there was no sex difference in the weight of the forebrain, which contains HVC and RA, we did not need to correct the anatomical measurements for brain size. For each animal (six females, eight males), the AR mRNA-defined HVC, the Nissldefined HVC, and the RA were measured with an image analysis system (Imatec, Munich, Germany). The borders of the HVC and RA are defined in general by the cytoarchitecture of the HVC and RA, respectively, which differs from the surrounding tissue (see Fig. 3). These cytoarchitectural differences were used to measure the size of the HVC and RA in one series of $40 \mu \mathrm{m}$ sections. The sections were viewed on a computer screen, the outlines of HVC or RA were drawn, and the size of the drawn areas were measured with the image analysis system. The volume of HVC and RA, respectively, was the sum of these measurements multiplied by the section thickness multiplied by 3 . Because the HVC was difficult to delineate in some of the Nissl-stained sections, particularly in females, we used in addition the distribution of androgen receptors (AR mRNA-defined HVC) to delineate and measure the HVC (see Fig. $3 C, D$ ). The AR mRNA-defined HVC was measured in the two series of $20-\mu \mathrm{m}$ sections. These measurements were performed as described for the Nissl-stained sections.

The number of neurons of the HVC and RA was counted in the Nissl-counterstained sections under high power $(1000 \times)$ with the help of the image analysis system on a video screen. Six $2000 \mu \mathrm{m}^{2}$ counting frames were analyzed in every third section of each animal using the optical dissector technique (Coggeshall, 1992), and the total number of cells was derived from these cell densities and the HVC volume. The size of neuron somatas was measured with the above image analysis system under high power $(1000 \times)$. Kruskal-Wallis nonparametric ANOVA (Conover, 1980) was used for all statistical comparisons of the morphometric measurements.

\section{RESULTS}

The volumes of the HVC and RA of a wild-caught male, a male offspring from a wild pair, and aviary-bred males were in the same range. Likewise, the volumes of a female, originating from a wild pair, and of females bred in captivity were similar (Fig. 2). Therefore, we analyzed together birds that were originally wild and birds bred in captivity.

The volumes of the HVC and RA were 1.8 and 2.0 times larger ( $p<0.01$ for both areas), respectively, in male compared with female shrikes (Figs. 2, 3): The size of the HVC (defined by AR mRNA distribution) was $0.16 \pm 0.008 \mathrm{~mm}^{3}$ for the males and $0.086 \pm 0.009$ for the females. Because the borders of the HVC were ambiguous in females in Nissl-stained material (calculated size: $0.045 \pm 0.02 \mathrm{~mm}^{3}$ ), we used only the AR mRNA-defined HVC for statistical comparisons to avoid an underestimation of the female HVC size. The size of the RA was $0.151 \pm 0.005$ for the males and $0.075 \pm 0.004 \mathrm{~mm}^{3}$ for the females. The size of the Nissl-defined nucleus hypoglossus was 1.3 larger in males $(0.03 \pm$ $\left.0.007 \mathrm{~mm}^{3}\right)$ compared with females $\left(0.023 \pm 0.005 \mathrm{~mm}^{3}\right)$. The neuron number of the male $\operatorname{HVC}(21,050 \pm 2765)$ and RA $(5547 \pm 825)$ was 1.5 and 1.4 times larger $(p<0.01$ for both areas), respectively, compared with the neuron number of the HVC $(13,820 \pm 3016)$ and RA $(3880 \pm 396)$ of females (Fig. 2). The repertoire sizes, however, do not differ between males and females. Thus, the number of song types produced by the shrikes does not correlate with either the HVC or RA size or the neuron numbers of these vocal control areas. The soma size of hypoglossus pars tracheosyringealis (nXIIts) neurons was $250 \pm 32 \mu \mathrm{m}^{2}$ in males and $245 \pm 45 \mu \mathrm{m}^{2}$ in females $(p>0.05)$. The soma size of RA neurons was not statistically different $(p>0.05)$ between males $\left(89.2 \pm 18.9 \mu \mathrm{m}^{2}\right)$ and females $\left(78.6 \pm 19.4 \mu \mathrm{m}^{2}\right)$ (Figs. 2, $3)$. In contrast, HVC neurons of males $\left(51.7 \pm 5.6 \mu \mathrm{m}^{2}\right)$ are significantly $(p<0.01)$ larger compared with those of females $\left(37.4 \pm 5.9 \mu \mathrm{m}^{2}\right)$ (Fig. 2).
The vocal areas of masculinized female zebra finches and female canaries are smaller compared with those of the males, although these females sing complex songs (Gurney, 1980, 1982; Gurney and Konishi, 1980; Nottebohm, 1980). In particular, in female canaries it was shown that such masculinization does not just induce male-like song pattern but these song patterns are functionally masculinized, i.e., sexually attractive to receptive female canaries (Vallet et al., 1996). Even in the "monomorphic" (concerning song repertoire) bay wren, $\mathrm{HVC}$ is still $30 \%$ larger in males compared with the females (Arnold et al., 1986). Because of these observations, the statistical analysis of the correlation of sex differences in HVC size, RA size, and song repertoire size was performed with all species for which these data are available at present (see Table 1). This kind of statistical analysis has not been performed previously.

First, there was no correlation between the repertoire size (measured as song type or syllable repertoire size) and the degree of sex difference (expressed as the maximum recorded for a species, as the midpoint of all measured sex differences for a species, or as the minimum sex difference measured for a species) for either HVC or RA on the data set as a whole (see Table 1) using the Pearson product-moment correlation coefficient (parametric correlation), Kendall's tau, or Spearman's rho (nonparametric correlations) ( $p>0.25$ in all cases), whether or not the comparisons included male-only singers. Because there was no correlation between the sex differences in the volume of brain areas and the vocal repertoire in the data set as a whole, we subdivided the species into four categories based on the sex difference in vocal behavior (Table 1 ): category I = male-only singers; category II = singing females, but the size of the female song repertoire is different from the male repertoire; category III = song repertoire size is similar in males and females; and category IV = hormone-induced male-like singing of females. The canary was placed in category II, although Nottebohm (1980) claimed that female canaries do not sing; Pesch and Güttinger (1985) and Vallet et al. (1996), however, demonstrated clearly that female canaries do sing spontaneously. For the whitethroated sparrow we used the data of the tan-striped male and the white-striped female color morph (DeVoogd et al., 1995). The use of white-striped male and tan-striped female pairs does not affect the results, assuming that these females, although they rarely sing (Falls and Kopachena, 1994), have on average one song type like the males.

Second, we ran the correlations (Pearson product-moment correlation coefficient, Kendall's tau, or Spearman's rho) between the repertoire size (measured as song type or syllable repertoire size) and the degree of sex differences for either HVC or RA within the categories I-IV. Because all tests were not significant ( $p>0.2$ in all cases) before correcting for multiple comparisons, they certainly would not be significant after such corrections.

Third, using parametric ANOVA we calculated whether sex differences of HVC or RA were related to whether the birds belonged to one of the four categories. There is significant heterogeneity in both cases. Post hoc tests (Bonferroni/Dunn) for HVC and RA show that the male-only singers have larger sex differences than the other three categories (for HVC: I, II, $p<$ 0.0001 ; I, III, $p<0.0001$; I, IV, $p=0.0003$; for RA: I, II, $p=$ 0.038 ; I, III, $p=0.022$; I, IV, $p=0.073$ ), which are not different from each other (for HVC: II, III, $p=0.6641$; II, IV, $p=0.9009$; III, IV, $p=0.8173$; for RA: II, III, $p=0.7463$; II, IV, $p=0.8742$; III, IV, $p=0.9159$; significance level $5 \%$ if $p$ value $<0.0083$ ). Because female white-crowned sparrows sing primarily outside 


\section{RA}
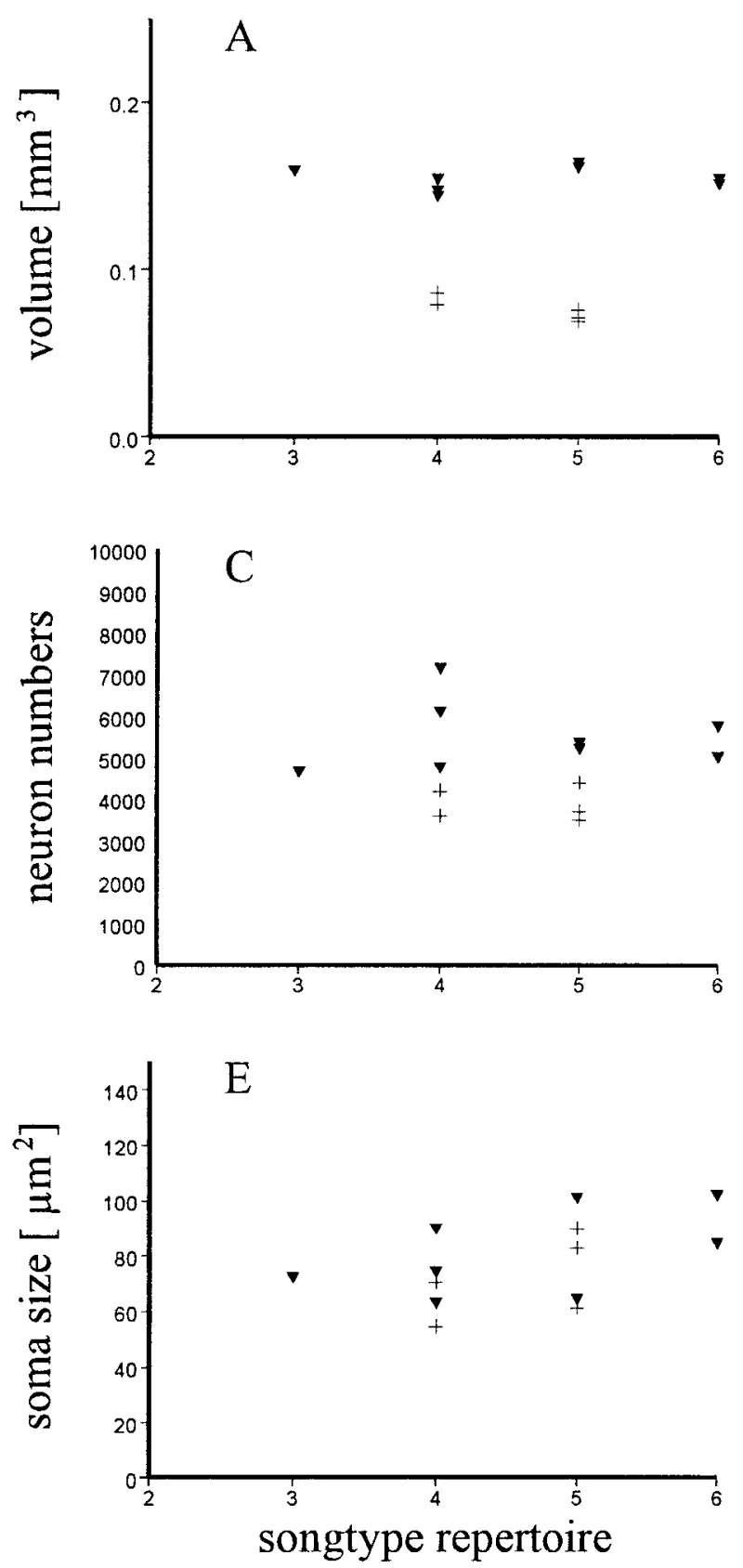

\section{HVC}
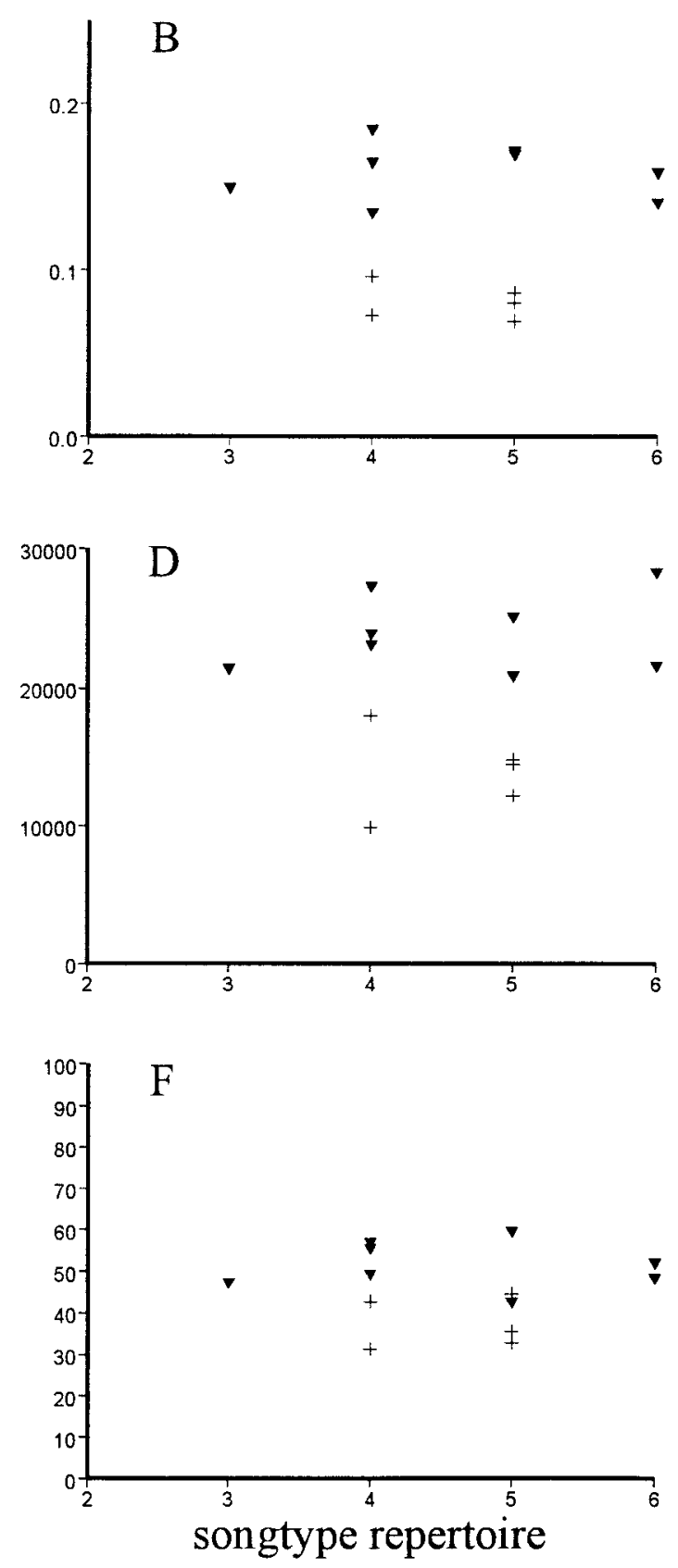

Figure 2. The volume, neuron number, and neuron soma size of HVC and RA of the shrike do not correlate with the repertoire size. Scatterpools relating the volumes of $\mathrm{HVC}(A)$ and $\mathrm{RA}(B)$, the neuron number of $\mathrm{HVC}(C)$ and $\mathrm{RA}(D)$, and the neuron soma size of $\mathrm{HVC}(E)$ and RA $(F)$ to repertoire size of male $(\boldsymbol{\nabla})$ and female $(+)$ shrikes. There is, however, a clear sex difference in the volume and neuron content of HVC and RA. Concerning neuron soma size, there is a sex difference in HVC but not in RA.

and at the beginning of the breeding season (Baptista et al., 1993) and because the anatomical study of this species (Baker et al., 1984) was performed in summer (breeding season), one could argue that this species should be placed in category I. In this case, and if canaries are put into category I according to Nottebohm (1980), there are no more differences between the male-only singers and the other categories.

This statistical analysis demonstrates that (1) the sex differences of song areas in species in which only males sing are larger than in species in which both sexes sing but (2) the sex differences of song areas and song repertoire are independent in species with singing females.

\section{DISCUSSION}

Despite the lack of sex differences in the repertoire size between male and female African bush shrikes, the forebrain vocal control areas HVC and RA are about twice the size and contain about twice as many neurons in males compared with females (Fig. 2). 

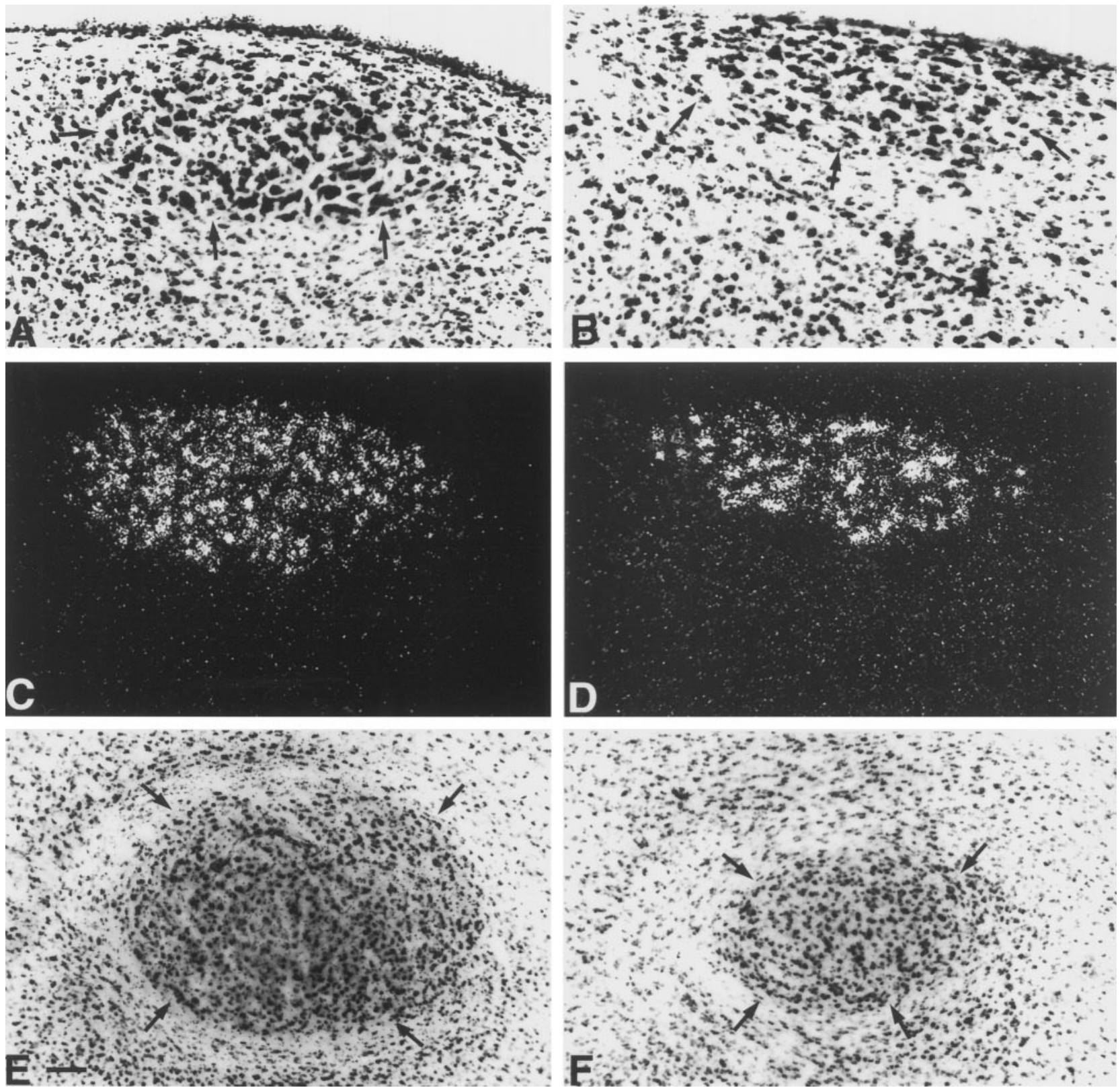

Figure 3. The total volume of both $\mathrm{HVC}$ and RA of all males was larger compared with all females. Photomicrographs of the Nissl-stained $\mathrm{HVC}(A$, $B)$, the androgen receptor expressing $\operatorname{HVC}(C, D)$, and the Nissl-stained RA $(E, F)$ of male $(A, C, E)$ and female $(B, D, F)$ shrikes. Arrows indicate the ventral borders of HVC and the outlines of RA in the Nissl-stained sections. For the HVC, we used the distribution of AR mRNA to delineate and measure the volume of this nucleus. The AR mRNA distribution (area of dense white silver grains in the dark-field image) clearly defines the HVC, whereas HVC is difficult to delineate in the Nissl stainings in some cases. The diameter of RA of the males was larger compared with the females throughout the entire nucleus. The dorsoventral diameter of HVC is almost similar in both sexes, but $\mathrm{HVC}$ of males is about twice as large in its mediolateral extension.

In contrast to the notion that brain space correlates with song complexity in songbirds, the present results suggest that the repertoire size does not correlate with the size of $\mathrm{HVC}$ and RA in the shrike. This conclusion is supported by the following observations.

First, physical characteristics of the song types do not allow a prediction of which will be male or which female, although birds in the field recognize and differentiate between the song types of the other sex (Wickler, 1972; Sonnenschein and Reyer, 1983). Second, although adult birds in the field as well as in captivity were never heard to produce the repertoire of their partners
(Wickler, 1972), aviary-raised birds at the song-learning stage pick up song types produced by a conspecific of the other sex, thus demonstrating that they are able to learn and produce song types of the opposite sex (Wickler and Sonnenschein, 1989). Thus there seems to be no sex difference in the complexity of song types (Wickler, 1972; Wickler and Seibt, 1988), despite the sex differences in the anatomy of HVC and RA. This result agrees with findings from male marsh wrens and zebra finches in which HVC and RA size develop independently of vocal learning (Burek et al., 1991; Brenowitz et al., 1995).

It was suggested previously that the size of the song nuclei 
Table 1. Sex differences in the size of vocal control areas do not correlate with sex differences in song

\begin{tabular}{|c|c|c|c|c|}
\hline \multirow[b]{2}{*}{ Species } & \multirow[b]{2}{*}{ RA } & \multirow[b]{2}{*}{ HVC } & \multicolumn{2}{|c|}{ Repertoire } \\
\hline & & & Male & Female \\
\hline \multicolumn{5}{|l|}{ I. Only the male sings } \\
\hline Zebra finch ${ }^{\mathrm{u}, \mathrm{b}, \mathrm{a}}$ & $11.9-5.5$ & $13.6-5.0$ & 1.2 & 0 \\
\hline Marsh wren ${ }^{\mathrm{r}, \mathrm{h}}$ & 5 & 10 & 53.6 & 0 \\
\hline Orange bishopbird $^{\mathrm{n}}$ & 29 & $>29$ & 1 & 0 \\
\hline \multicolumn{5}{|l|}{$\begin{array}{l}\text { II. Female song repertoire size } \\
\text { differs from the male }\end{array}$} \\
\hline Canary ${ }^{\mathrm{u}, \mathrm{c}, \mathrm{k}}$ & $3.0-2.7$ & $4.3-2.7$ & $30-20$ & $35-5$ \\
\hline Red-winged blackbird ${ }^{\mathrm{g}, \mathrm{o}}$ & 4.7 & 3.2 & 5.9 & 2 \\
\hline White-browed robin chat ${ }^{\mathrm{i}, \mathrm{d}}$ & 2.4 & 2.9 & 40 & 3.5 \\
\hline Rufous and white wren ${ }^{1, e}$ & 2.2 & 1.7 & 14 & 6 \\
\hline Starling ${ }^{\mathrm{p}, \mathrm{t}}$ & 1.7 & 1.6 & 46.4 & 24 \\
\hline \multicolumn{5}{|c|}{$\begin{array}{l}\text { III. Similar repertoire size in male } \\
\text { and female }\end{array}$} \\
\hline Red-checked cordon blue ${ }^{\mathrm{j}, \mathrm{m}}$ & 1.4 & 1.5 & 1.3 & 1.2 \\
\hline White-crowned sparrow ${ }^{\mathrm{f}, \mathrm{q}}$ & 3.7 & 2.4 & 1 & 1 \\
\hline White-throated sparrows & 1.5 & 1.9 & 1 & 1 \\
\hline Buff-breasted wren ${ }^{\mathrm{i}, \mathrm{e}}$ & 1.5 & 1.3 & 13 & 11.7 \\
\hline Bay wren ${ }^{1, e}$ & 1.1 & 1.5 & 16.5 & 15.2 \\
\hline Bush shrike (this study) & 2.0 & 1.8 & 4.6 & 4.5 \\
\hline \multicolumn{5}{|l|}{$\begin{array}{l}\text { IV. Hormone-induced male-like } \\
\text { singing of females }\end{array}$} \\
\hline Masculinized canary ${ }^{\mathrm{u}, \mathrm{c}, \mathrm{k}}$ & $2.1-1.9$ & $2.3-2.0$ & $30-20$ & $35-5$ \\
\hline Masculinized zebra finch ${ }^{\mathrm{u}, \mathrm{b}}$ & $1.9-1.6$ & $1.8-1.6$ & 1.2 & 1.2 \\
\hline
\end{tabular}

Listed is the male-to-female ratio of the volume of the HVC and the RA. Repertoire size (means of real values) comprises number of song types in each species except for the starling and the canary, in which syllable repertoire is given as the song type repertoire of females in these species is unknown. For the canary and the zebra finch the range of values is given, because these species have been studied in several investigations with quite different results. Statistical comparisons (see Results) demonstrate that sex differences in species in which only the males sing are greater than in species in which females also sing, but sex differences in HVC and RA are independent of the vocal behavior in species with singing females. The data originate from the following sources: a, Nottebohm and Arnold, 1976; b, Gurney, 1980; c, Nottebohm, 1980; d, Todt et al., 1981; e, Farabaugh, 1982, 1983; f, Baker et al., 1983; g, Beletsky, 1983; h, Canady et al., 1984; i, Brenowitz et al., 1985; j, Gahr and Güttinger, 1985; k, Pesch and Güttinger, 1985; 1, Brenowitz and Arnold, 1986; $\mathrm{m}$, Gahr and Güttinger, 1986, and unpublished data; n, Arai et al., 1989, and personal communication; o, Kirn et al., 1989; p, Bernard et al., 1993; q, Baptista et al., 1993; r, Brenowitz et al., 1994; s, DeVoogd et al., 1995; t, Hausberger et al., 1995; u, M. Gahr, unpublished data.

limits the amount of vocalizations that could be maximally learned and that laboratory work leads to abnormally small repertoires (Brenowitz et al., 1995). Thus, we need to compare the vocal behavior of wild and captive shrikes.

In free-living bush shrikes, the repertoire size of different geographic populations is different. In several Kenyan populations, females sing fewer song types than males do, whereas in some Tanzanian populations and in a population at Lake Victoria, males and females have repertoires of similar size that are both larger than those of the other Kenyan populations (Wickler, 1972; Sonnenschein and Reyer, 1983; E. Sonnenschein and U. Reyer, unpublished data). In captivity, however, male and female shrikes learn to produce songs different from those of their parental population with regard to number of song types, i.e., females may have larger repertoires than their parental population (Wickler and Sonnenschein, 1989). In captivity, female offspring of the Kenyan population learned to sing as many song types as the males. Thus the population differences in the degree of sex-specific repertoire size in the bush shrike reflect population differences in vocal learning but not neural limitations of the learning capabilities. The factors that guide sex-specific song learning under natural conditions in the shrike are unknown (Wickler and Lunau, 1997). Furthermore, the repertoire size of the wild-caught male included in this study is in the range of the males raised in captivity. We conclude, therefore, that female and male bush shrikes are able to learn the same repertoire.

Do the present results mean then that the shrike is an exception to the rule that sex differences in the size of song areas correlate with sex differences in song repertoire size or complexity of songbirds? Statistical analysis of the sex differences of the song complexity and the size of forebrain vocal control areas among songbirds gives a rather surprising result (Table 1). The sex difference in brain area size in species in which only the males sing is larger than in species in which females also sing, but the sex differences in brain area size is independent of the vocal behavior in species with singing females. This literature analysis suggests that the shrike is not the exception to the rule but that there is no rule, i.e., no correlation between repertoire size and the degree of sex difference in HVC and RA size if females do sing. Consequently, similar to the shrike, neuron numbers of forebrain vocal areas should not correlate with sex differences in the song repertoire of other songbirds in which females sing. Furthermore, the statistical analysis suggests that HVC and RA need to obtain an adequate size to allow song production. Beyond this point, the size and neuron number of forebrain vocal areas HVC and RA do not predict the singing behavior.

In the following discussion we examine the possibility that sex differences in the anatomy of the forebrain vocal control areas correlate with other features of singing, such as loudness and song activity. We can exclude loudness in the shrikes, but song rates are always higher in male than in female bush shrikes, independent of their individual repertoire size (Sonnenschein and Reyer, 1983; E. Sonnenschein and U. Reyer, unpublished data). The correlation between the rate of singing and the morphology of vocal control areas was studied recently in a comparative analysis using two color morphs (white-striped and tan-striped) of the white-throated sparrow (DeVoogd et al., 1995). Tan-striped males and their whitestriped females have similar song behavior with regard to both quality and quantity of song. White-striped males sing frequently, but their tan-striped mates sing rarely, if ever (Falls and Kopachena, 1994). HVC and RA as well as the other forebrain vocal control areas, however, are sexually dimorphic in both pairs of color morphs, despite monomorphic singing of the tan-striped male/white-striped female pair (Table 1). Only the motonucleus hypoglossus (nXIIts) correlates with the singing rate because it is similar in size in the tan-striped male/white-striped female pair (similar singing rate) and sexually dimorphic in the pair with the sexually dimorphic singing activity (white-striped male/tan-striped female) (DeVoogd et al., 1995). Similar to that of the whitethroated sparrow, the nXIIts of the shrike is slightly larger in males than in females. Thus the singing rate might correlate with features of the nXIIts, which controls the sound-producing syringeal muscles (but see below). It is unlikely, however, that the number of neurons in a sensorimotor integration area such as the HVC (which is at least three synapses upstream from the soundproducing muscles) correlates with the frequency of motor activity. This view is further supported by the finding that the development of the size of the forebrain vocal control nuclei HVC and RA of the zebra finch is independent from the development of the syrinx and the nXIIts (Lohmann, 1997).

A further possibility is that the sex difference in the size of 
HVC and RA of the shrike and of other songbirds is related to sound perception rather than to sound processing. Vocal areas are important for the perception of song. In correlation, some of the most complex auditory neurons known are contained in the HVC (e.g., Margoliash and Fortune, 1992; Lewicki and Arthur, 1996). In particular, there is a substantial increase in the auditory temporal context sensitivity between field L (the highest, purely auditory center of birds) and HVC (Lewicki and Arthur, 1996). In dueting species such as the bush shrike or the bay wren, such auditory neurons are required in both sexes to sing the duet. Thus, we cannot assume that perceptual properties of males and females are different in the shrike, because the passive song repertoire must be similar in male and female of dueting species. Last, in female marsh wrens that do not sing, the size of vocal areas of females that perceive large repertoires and of females that perceive small repertoires during development and adulthood is similar (Brenowitz et al., 1994).

If area size and neuron numbers do not, then do neuronal features correlate with the song repertoire? In species with monomorphic singing behavior, the ultrastructure of neurons was reported to be quite similar between the sexes (DeVoogd et al., 1988). In the shrike, soma size of RA and nXIIts neurons is similar between sexes and therefore seems to correlate with the similar size and physical characteristics of the vocal repertoire of males and females. In contrast to the RA, the soma size of HVC neurons is sexually dimorphic, and therefore HVC soma size does not correlate with the monomorphic size and physical characteristics of the vocal repertoire. Thus females produce a similar vocal pattern with fewer and smaller neurons in their $\mathrm{HVC}$ but with similar-sized neurons in the RA. In summary, the most parsimonious explanation for the shrike data as well as for previous work on sex differences in other songbird species is that there is no simple relation between area size, neuron number, neuron soma size of forebrain vocal control areas, and the vocal complexity in songbirds.

A possible explanation for this lack of a simple relationship between brain area size, neuron number, neuron phenotype, and singing is that the forebrain vocal control areas are multifunctional and that some of these functions, in addition to song control, differ in males and females; e.g., all of the forebrain vocal control areas contain auditory neurons (Doupe and Konishi, 1991). In addition to the auditory input, HVC seems to receive visual (Bischof and Engelage, 1985) and somatosensory information via the thalamic nucleus uvaeformis (Wild, 1994b). Furthermore, neurons in many song areas process endocrine information (Gahr and Kosar, 1996; Gahr and Metzdorf, 1997). Consequently, the comparative (male to female comparison) approach for the study of neural mechanisms of vocal control should focus on sex differences between functionally defined neuron populations within the vocal control areas rather than on brain area size and neuron numbers. A further possibility to explain the lack of a correlation between brain area size and behavior is that the evolution of the size and physical complexity of the vocal repertoire is attributable to the evolution of the complexity of neurons rather than the evolution of brain space and neuron numbers. To solve this problem, experimental approaches are necessary to define the anatomical units of sound generation in male and female birds.

In summary, in the bush shrike as well as in all other songbird species in which females sing, there is no correlation between sex differences in the song repertoire and size of song control areas. We cannot rule out that there are sex differences in vocal properties that were not studied and that would correlate with the sex differences in size and neuron numbers of the vocal control areas. These vocal properties, however, must be different from song repertoire size, physical properties of elements, song loudness, and singing frequency. At present, the songbird model does not support the notion that sex differences in brain area size and neuron number explain sex differences in a behavior that occurs in both sexes.

\section{REFERENCES}

Arai O, Taniguchi I, Saito N (1989) Correlations between the size of song control nuclei and plumage color change in orange bishop birds. Neurosci Lett 98:144-148.

Arnold AP, Gorski R (1984) Gonadal steroid induction of structural sex differences in the CNS. Annu Rev Neurosci 7:413-442.

Arnold AP, Bottjer SW, Brenowitz EA, Nordeen EJ, Nordeen KW (1986) Sexual dimorphisms in the neural vocal control system in song birds: ontogeny and phylogeny. Brain Behav Evol 28:22-31.

Baker MC, Bottjer SW, Arnold AP (1984) Sexual dimorphism and lack of seasonal changes in vocal control regions of the white-crowned sparrow brain. Brain Res 295:85-89.

Ball GF, Casto JM, Bernard DJ (1994) Sex differences in the volume of avian song control nuclei: comparative studies and the issue of brain nucleus delineation. Psychoneuroendocrinology 19:485-504.

Baptista LF, Trail PW, Dewolfe BB, Morton ML (1993) Singing and its functions in female white-crowned sparrows. Anim Behav 46:511-524.

Beletsky LD (1983) Aggressive and pair-bond maintenance songs of female red-winged blackbirds (Agelaius phoeniceus). Z Tierpsychol 62:47-54.

Bernard DJ, Casto JM, Ball GF (1993) Sexual dimorphism in the volume of song control nuclei in European starlings: assessment by a Nissl stain and autoradiography for muscarinic cholinergic receptors. J Comp Neurol 334:559-570.

Bischof HJ, Engelage J (1985) Flash evoked responses in a song control nucleus of the zebra finch (Taeniopygia guttata catanotis). Brain Res 326:370-374.

Brenowitz EA, Arnold AP (1986) Interspecific comparisons of the size of neural song control regions and song complexity in duetting birds: evolutionary implications. J Neurosci 6:2875-2879.

Brenowitz EA, Arnold AP, Levin RN (1985) Neural correlates of female song in tropical duetting birds. Brain Res 343:104-112.

Brenowitz EA, Nalls B, Kroodsma DE, Horning C (1994) Female marsh wrens do not provide evidence of anatomical specializations of song nuclei for perception of male song. J Neurobiol 25:197-208.

Brenowitz EA, Lent K, Kroodsma DE (1995) Brain space for learned song in birds develops independently of song learning. J Neurosci 15:6281-6286.

Burek MJ, Nordeen KW, Nordeen E (1991) Neuron loss and addition in developing zebra finch song nuclei are independent of auditory experience during song learning. J Neurobiol 56:240-250.

Canady RA, Kroodsma DE, Nottebohm F (1984) Population differences in complexity of a learned skill are correlated with the brain space involved. Proc Natl Acad Sci USA 81:6232-6234.

Coggeshall RE (1992) A consideration of neural counting methods. Trends Neurosci 15:9-13.

Conover RE (1980) Practical non-parametric statistics, Ed 2. New York: Wiley.

DeVoogd TJ, Brenowitz EA, Arnold AP (1988) Small sex differences in song control dendrites are associated with minimal differences in song capacity. J Neurobiol 19:199-209.

DeVoogd TJ, Houtman AM, Falls JB (1995) White-throated sparrow morphs that differ in song production rate also differ in the anatomy of some song-related brain areas. J Neurobiol 28:202-213.

Doupe AJ, Konishi M (1991) Song-selective auditory circuits in the vocal control system of the zebra finch. Proc Natl Acad Sci USA 88:11339-11343.

Falls JB, Kopachena JG (1994) White throated sparrows (Zonotrichia albicollis). Birds North Am 128:1-32.

Farabaugh SM (1982) The ecological and social significance of duetting. In: Acoustic communication in birds, Vol 2 (Kroodsma DE, Miller EH, eds), pp 85-124. New York: Academic.

Farabaugh SM (1983) A comparative study of duet song in tropical Thryothorus wrens. PhD thesis, University of Maryland. 
Francis RC (1995) Evolutionary neurobiology. Trends Ecol Evol 10:276-281.

Gahr M (1994) Brain structure: causes and consequences of brain sex. In: The differences between the sexes (Short RV, Balaban E, eds), pp 273-302. Cambridge, UK: Cambridge UP.

Gahr M (1997) How should brain nuclei be delineated? Consequences for developmental mechanisms and for correlations of area size, neuron numbers and functions of brain nuclei. Trends Neurosci 20:58-62.

Gahr M, Güttinger HR (1985) Korrelation zwischen der sexualdimorphen Gehirndifferenzierung und der Verhaltensausprägung bei Prachtfinken (Estrildidae). J Ornithol 126:310.

Gahr M, Güttinger HR (1986) Functional aspects of singing in male and female Uraeginthus bengalus (Estrildidae). Ethology 72:123-131.

Gahr M, Kosar E (1996) Identification, distribution, and developmental changes of a melatonin binding site in the song control system of the zebra finch. J Comp Neurol 367:308-318.

Gahr M, Metzdorf R (1997) Distribution and dynamics in the expression of androgen- and estrogen receptors in vocal control systems of songbirds. Brain Res Bull 44:509-517.

Gahr M, Metzdorf R, Aschenbrenner S (1996) The ontogeny of the canary $\mathrm{HVC}$ revealed by the expression of androgen and estrogen receptors. NeuroReport 8:311-315.

Gurney ME (1980) Sexual differentiation of brain and behavior in the zebra finch (Peophila guttata): a cellular analysis. PhD thesis, California Institute of Technology.

Gurney ME (1982) Behavioral correlates of sexual differentiation in the zebra finch song system. Brain Res 231:153-173.

Gurney ME, Konishi M (1980) Hormone-induced sexual differentiation of brain and behavior in the zebra finches. Science 208:1380-1383.

Hausberger M, Richard-Yris MA, Henry L, Lepage L, Schmidt I (1995) Song sharing reflects the social organization in a captive group of European starlings (Sturnus vulgaris). J Comp Psychol 109:222-241.

Kelley DB, Brenowitz E (1992) Hormonal influences on courtship behaviors. In: Behavioral endocrinology (Becker JB, Breedlove SM, Crews D, eds), pp 187-218. Cambridge, MA: MIT.

Kirn JR, Clower RP, Kroodsma DE, De Voogd TJ (1989) Song-related brain regions in the red-winged blackbird are affected by sex and season but not repertoire size. J Neurobiol 20:139-163.

Lewicki MS, Arthur BJ (1996) Hierarchical organization of auditory temporal context sensitivity. J Neurosci 16:6987-6998.

Lohmann R (1997) Significance of the syringeal muscles during the steroid-dependent development of the sexual dimorphic neural song control system and song in the zebra finches. PhD thesis, LudwigMaximilian-University Munich.

Margoliash D, Fortune ES (1992) Temporal and harmonic combinationsensitive neurons in the zebra finch's HVC. J Neurosci 12:4309-4326.

Nastiuk KL, Clayton DF (1994) Seasonal and tissue-specific regulation of canary androgen receptor mRNA. Endocrinology 134:640-649.
Nastiuk KL, Clayton DF (1995) The canary androgen receptor mRNA is localized in the song control nuclei of the brain and is rapidly regulated by testosterone. J Neurobiol 26:213-224.

Nottebohm F (1980) Testosterone triggers growth of brain vocal control nuclei in adult female canaries. Brain Res 189:429-436.

Nottebohm F, Arnold AP (1976) Sexual dimorphism in vocal control areas of the songbird brain. Science 194:211-213.

Nottebohm F, Stokes TM, Leonard CM (1976) Central control of song in the canary, Serinus canaris. J Comp Neurol 165:457-486.

Pesch A, Güttinger HR (1985) Der Gesang des weiblichen Kanarienvogels. J Ornithol 126:108-110.

Raisman F, Field PM (1971) Sexual dimorphism in the neuropil of the preoptic area of the rat and its dependence on neonatal androgen. Brain Res 54:1-29.

Sonnenschein E, Reyer U (1983) Mate-guarding and other functions of antiphonal duets in the slate-coloured boubou (Lanarius funebris). Z Tierpsychol 63:112-140.

Todt D, Hultsch H, Duvall II EP (1981) Behavioural significance and social function of vocal and non-vocal displays in the monogamous duet-singer Cossypha heuglini H. Zool Beitr 27:426-428.

Vallet E, Kreutzer M, Gahr M (1996) Testosterone induces sexual release quality in the song of female canaries. Ethology 102:617-628.

Vu ET, Mazurek ME, Kuo YC (1994) Identification of a forebrain motor programming network for the learned song of zebra finches. J Neurosci 14:6924-6934.

Whitfield Jr HJ, Brady LS, Smith MA, Mamalaki E, Fox RJ, Herkenham M (1990) Optimization of cRNA probe in situ hybridization methodology for localization of glucocorticoid receptor mRNA in rat brain: a detailed protocol. Cell Mol Neurobiol 10:145-157.

Wickler W (1972) Aufbau und Paarspezifität des Gesangsduettes von Lanarius funebris. Z. Tierpsychol 30:464-476.

Wickler W, Lunau K (1997) How do East African bush shrikes Lanarius funebris recognize male and female tutors during gender dialect development? Naturwissenschaften 84:1-2.

Wickler W, Seibt U (1988) Gender dialects: a new phenomenon from birdsong epigenesis. Naturwissenschaften 75:51-52.

Wickler W, Sonnenschein E (1989) Ontogeny of song in captive duetsinging slate-coloured boubous (Lanarius funebris). Behaviour 111:220-233.

Wild JM (1994a) The auditory-vocal-respiratory axis in birds. Brain Behav Evol 44:192-209.

Wild JM (1994b) Visual and somatosensory inputs to the avian song system via nucleus uvaeformis (Uva) and a comparision with the projections of a similar thalamic nucleus in a nonsongbird, Columba livia. J Com Neurol 349:512-535.

Yu AC, Margoliash D (1996) Temporal hierarchical control of singing in birds. Science 273:1871-1875. 